\title{
La cultura material de la escolarización: reflexiones en torno a un giro historiográfico ${ }^{1}$
}

\section{A cultura material da escolarização: reflexões em torno da virada historiográfica}

\author{
The material culture of schooling: \\ reflections around a historiographic turn
}

\author{
Inés Dussel ${ }^{*}$
}

\begin{abstract}
RESUMEN
En este artículo se analizan algunos presupuestos teóricos y metodológicos del giro material en la historia de la educación. Se debate su novedad respecto a aproximaciones anteriores sobre la materialidad y espacialidad de lo escolar; se subrayan dos aspectos originales, que son: (a) inscribir a los objetos en trayectorias que dan cuenta de sus movimientos en redes de relaciones entre humanos y no humanos, y (b) considerar no solamente las relaciones de sentido, sino también los efectos de la co-presencia e interacción visible y sensible entre los investigadores y los registros del pasado. En el siguiente apartado se presentan reflexiones sobre el uso de las fotografías como fuentes históricas desde la perspectiva del giro material, tomando como ejemplo la investigación desarrollada sobre los uniformes escolares. Finalmente, en las conclusiones se retoman dos breves textos de Walter Benjamin y Michel Foucault sobre la materialidad de los objetos y los espacios para formular nuevas preguntas a la historia de la educación.
\end{abstract}

1 Este texto retoma algunos argumentos preparados para el libro Balances de Historiografía Educativa, editado por Nicolás Arata y Pablo Pineau, de próxima aparición en Argentina. Agradezco a los editores el permiso para republicar algunas de las ideas que se editarán en ese libro.

* Centro de Investigación y Estudios Avanzados del Instituto Politécnico Nacional. Departamento de Investigaciones Educativas del CINVESTAV-IPN. Cidade do México, México. Email: idussel@gmail.com. https://orcid.org/0000-0003-3983-3985. 
Palabras clave: Historia de la educación. Escuela. Cultura material. Historiografía. Fotografías como fuente histórica.

\title{
RESUMO
}

Neste artigo são analisados alguns pressupostos teóricos e metodológicos da virada material na história da educação. Debate-se sua novidade a respeito das aproximações anteriores sobre a materialidade e espacialidade do escolar; salientam-se dois aspectos originais, que são: (a) inscrever os objetos em trajetórias que coloca-os em movimento em redes de relações entre humanos e não humanos, e (b) considerar não somente as relações de sentido, mas também os efeitos da copresença e interação visível e sensível entre os investigadores e os registros do passado. No segundo momento, são apresentadas reflexões sobre o uso das fotografias como fontes históricas desde a perspectiva da virada material, tomando como exemplo a investigação desenvolvida sobre os uniformes escolares. Finalmente, nas conclusões, são retomados dois textos breves de Walter Benjamin e Michel Foucault sobre a materialidade dos objetos e dos espaços para formular novas perguntas à história da educação.

Palavras-chave: História da educação. Escola. Cultura material. Historiografia. Fotografia como fonte histórica.

\begin{abstract}
The article presents an analysis of some of the main theoretical and methodological tenets of the material turn in the history of education. It discusses whether this approach is new or continues older takes on the materiality and spatiality of schooling; what appears as original are (a) the inscription of objects in trajectories that sets them in movement in networks of human and non-humans, and (b) considering not only meaning-production but also the effects of the co-presence and co-mingling of researcher and objects on a visible and sensible level. The text introduces some reflections about the use of photographs as historical sources considered from the point of view of the material turn, taking as a thread the author's research on school uniforms. Finally, in the concluding remarks, two short texts on materials and objects from Walter Benjamin and Michel Foucault are included, and their relevance for the rethinking of objects and spaces is underscored, along with their fertility to pose new questions to the history of education.
\end{abstract}

Keywords: History of education. School. Material culture. Historiography. Photographs as historical source. 


\section{La escuela como espacio material}

En una de las primeras obras modernas de pedagogía, el Orbis Sensualium Pictus, de Comenio, se presenta una definición de escuela que sintetiza varios de sus rasgos modernos. El texto, concebido por Comenio como un medio de dotar a la enseñanza de un conjunto de imágenes y palabras para estabilizar el sentido del mundo y de la escuela (Aguirre Lora, 2001), fue publicado en Nuremberg en 1658 y un año después se tradujo al inglés, con una edición bilingüe inglés-latín. En esa edición, aparece en el capítulo XCVII (97) la entrada "Schola" o "A School", en la cual se dice que la escuela:

es una tienda [shop, officina o taller en latín] en el que las jóvenes almas se forman en la virtud y son distinguidas en clases [forms, también bancos]. El maestro [preceptor en latín] se sienta en una silla [cathedra en latín], los discípulos en bancos [subselliis en latín, asientos]; él enseña, ellos aprenden. Algunas cosas se escriben frente a ellos en una tableta [table en inglés]. Algunos se sientan en la mesa y escriben; él corrige sus faltas. Algunos entregan y ensayan o recitan cosas que se les ha mandado memorizar. Algunos hablan entre ellos y se comportan de manera petulante y negligente; éstos son castigados con una férula y una verga. (disponible en www.centromanes.org)

En esta descripción, llama la atención la presencia masiva de los objetos y las prácticas escolares, que superan ampliamente las referencias a los aspectos inmateriales de la enseñanza. En la imagen - disponible en línea -, la disposición del espacio es llamativa: el maestro está al frente, pero los alumnos tienen al menos tres espacios distintos entre los cuales pueden moverse - los bancos, la mesa y el frente para la recitación de memoria - y no parecen estar fijos en un solo lugar (como de hecho tampoco lo estaban en el aula llamada tradicional). En la presentación de Comenio de la escuela, los objetos apoyan ciertas prácticas: la pizarra y la mesa se usan para escribir, los bancos para leer y conversar. El maestro tiene una silla desde donde escucha las recitaciones y un atril en el que puede apoyar su libro. Puesta en serie con la historia de los asientos, es evidente que la silla magisterial mantiene algo del privilegio real del trono, ya que se distingue claramente de los bancos colectivos de los estudiantes.

La fuente también puede interrogarse desde el diálogo entre la imagen y las palabras, y entre distintas lenguas. En relación al primero, hay varios silen- 
cios significativos: el texto no menciona el atril, como tampoco menciona la vestimenta de los alumnos o del maestro, aunque pueden verse capas, calzado y un notorio sombrero en el maestro. Tampoco se hace referencia verbal a las ventanas, un elemento que luego sería constitutivo del aula (Van Den Driessche, 2009; Dussel, 2018); por esta ausencia, puede presumirse que el espacio de la escuela no parece estar fijo en un tipo de edificio particular, sino que su especificidad se define más bien por los objetos móviles, y sobre todo por los que hoy consideraríamos como artefactos didácticos, como los libros y la pizarra. En cuanto a las lenguas, la traducción permite mirar cierta inestabilidad en los significados: en inglés, los forms pueden ser clases o bancos (mientras que en latín tienen dos nombres distintos), en consonancia con las primeras formas de organización del aula a partir de filas de asientos y no de espacios separados (Fernández Enguita, 2017). La cátedra del latín se convierte en inglés en una silla del mobiliario, aunque la equivalencia entre Chair y cátedra se sostiene en las universidades anglosajonas hasta hoy. La ambigüedad entre tienda (traducción al inglés) y oficina o taller (en latín) es también significativa; como bien lo ha notado Santoni Rugiu (1994), el maestro fue mucho tiempo considerado un artesano, y su oficio era un arte que debía aprenderse siguiendo reglas formativas particulares. Es probable que la caracterización como tienda [shop] haya venido del pago que recibían los maestros, algo que desde la Edad Media venía reprochándoseles a los profesores universitarios. ${ }^{2}$

Queda claro, entonces, que la escuela moderna implicó la conformación de un espacio-tiempo con objetos específicos, y que su materialidad ha sido un aspecto subrayado por los pedagogos desde hace varios siglos. Si esta materialidade no es un tema nuevo, lo que muchos estudios contemporâneos aportan es una indagación más profunda sobre cómo se constituyó y qué efectos produjo esa materialidad y espacialidad de lo escolar.

¿De qué se trata este nuevo giro teórico y metodológico que vuelve a mirar a la escuela desde la cultura material escolar? La inspiración principal de esta perspectiva viene de distintas corrientes: la historia social de los objetos (Appadurai, 1986), la perspectiva foucaultiana sobre la microfísica del poder (Foucault, 1976) y la Teoría del Actor en Red (Latour, 2005), así como de una nueva sensibilidad sobre las texturas y detalles de la cultura que toma su impulso de la obra de Walter Benjamin (2005) y de la historia multisensorial (Grosvenor, 2012; Vidal y Gaspar da Silva, 2011). Con esta base teórica conceptual, desde

2 Etienne de Tournai criticaba a los maestros de la Universidad de Paris en el siglo XIII porque se habían convertido en "mercaderes de palabras (venditores verborum)" (en Le Goff, 1986, pp. 67-68). 
hace unos años la investigación histórico-educativa se ocupa cada vez más de la materialidad de la educación, prestando atención a la importancia de los edificios, las paredes, los pupitres, los pizarrones, los cuadernos, los recursos visuales o los uniformes y las vestimentas en la escuela y fuera de ella. Esta materialidad es considerada en primer lugar como objeto de estudio, pero también como fuente para la comprensión de procesos educativos más amplios y no solamente escolares, como los estudios sobre la cultura escrita en la escuela que analizan la producción y circulación de libros de texto, cuadernos de clase, revistas ilustradas o la difusión de las bibliotecas, y las investigaciones sobre la historia educativa del cine o de la educación estética que toman en cuenta la materialidad de los soportes y espacios en que se producen estas prácticas. ${ }^{3}$

Pueden señalarse al menos dos consecuencias de asumir el giro material en la historiografía educativa, que permite romper con el fetichismo de lo material o la mirada anticuaria. ${ }^{4}$ En primer lugar, el giro material supone incluir a los objetos y las cosas como partícipes plenos en la red de lo social, como actores o actantes -como los llama Latour (2005)- que no son sólo ni principalmente la proyección de nuestras acciones sino que también nos hacen realizar acciones o sentir emociones. Hay una simetría en esa interacción humanos-objetos que hay que considerar como punto de partida de la investigación; en esa dirección, habría que ir más allá de decir que la historia de un artefacto depende de los usos y sentidos que les damos a los objetos y buscar atender a lo que ese artefacto produjo en la nueva red humanos-objetos que se creó a partir de su presencia. En otras palabras, el giro material no busca animar lo inanimado (no es que de pronto los objetos 'cobren vida'), sino darles a los objetos un espesor y una

3 Véase, por ejemplo, la historia del pizarrón que escribió, para el caso brasileño, Valdeniza Barra (2016), o la del pupitre que hicieron en España Pedro Moreno Martínez (2005), en Italia Juri Meda (2016), y en Brasil Raquel Castro y Vera Gaspar da Silva (2012), así como también algunos estudios sobre modelos de banco como como los de Vottero (2017) y los objetos escolares (Gaspar da Silva y Petry, 2012). El trabajo de Granja Castro (2012) exhuma algunas máquinas y artefactos de enseñanza de un corpus poco explorado como son las patentes de inventores. Sobre libros, cuadernos, bibliotecas y otros registros de la cultura impresa, véanse, entre muchos, Cucuzza y Pineau (2002); Chartier (2004); Gvirtz (1999); Szir (2007); Arata (2016). Sobre el cine y la estética de las escuelas, puede consultarse Serra (2011); Pineau (2014); Monfort (2017). Los trabajos recientes sobre la cultura material de la escuela son numerosos, y no podría ni pretendo ser exhaustiva en esa enumeración. Señalé solamente algunos estudios que fueron importantes en mis investigaciones, a los que se irán agregando otros en los párrafos siguientes. Espero que este listado, aunque incompleto, invite a los lectores a sumar otros trabajos relevantes en sus propios recorridos de investigación.

4 Se retoman en esta pregunta los planteos de Agustín Escolano (2012), investigador español que ha sido pionero tanto en la investigación como en la organización de archivos y museos de la cultura material escolar. 
capacidad de acción no intencionada pero influyente en el curso de la historia humana. Somos lo que somos por la interacción con los objetos, así como ellos lo son por esas interacciones. ${ }^{5}$

En segundo lugar, el giro material implica reconceptualizar la temporalidad de los objetos mismos. En algunas teorías contemporáneas, que son probablemente las más interesantes para estudiar la presencia y acción de las cosas (por ejemplo Miller, 2005; Ingold, 2012), los objetos no son primero materiales y luego adquieren un sentido; más bien, "la materia constriñe el significado y viceversa" (Daston, 2006, p. 17). Debatiendo con quienes ven a los objetos o las cosas como entidades totalmente definidas y estáticas, estas teorías los consideran devenires nunca realizados por completo. Este proceso de devenir no es secuencial, como cuando se cree que primero estamos nosotros, y luego, como el reflejo en un espejo, los objetos. Al contrario: los objetos, tanto como los humanos, también están en movimiento, tienen una historia que no es previa a los sentidos que se construyen sobre ellos ni a las redes en que se inscriben.

Esto lleva también a repensar el vínculo entre forma y materia, ya no en términos de continente y contenido o de envoltorio e interior, sino como un continuo de la vida que se entrelaza y define mutuamente. Por ejemplo, Tim Ingold, uno de los antropólogos más importantes de la actualidad y un referente de estos estudios, señala que puede encontrarse movimiento o devenires en los vestigios arqueológicos. La cerámica "respira" y sigue modificándose en contacto con la arena o el barro donde se encuentra enterrada; no solamente cambia la forma (como en el tránsito de ser una vasija en uso, a un fragmento enterrado, a un objeto dispuesto en un museo) sino que también cambia la materia (Ingold, 2013). Ingold plantea que la teoría y la investigación tienen que materializar la vida humana y "ecologizar" la cultura: ésta no es una trama de significados que está en un espacio que tiene como fondo estático la naturaleza, sino que "la producción de sentido se da por el compromiso y la inmersión de los sujetos en el mundo inmediato y material de la experiencia" (Steil y Carvalho, 2015, p. 50). Esa inmersión modifica la experiencia humana profundamente, tanto como

5 Esta perspectiva tiene vínculos con el materialismo histórico marxista, aunque la concepción de los objetos en esa corriente sea bastante distinta a la que se presenta en este texto. Por ejemplo, Vygotski destacó la importancia de las herramientas materiales y simbólicas (incluyendo en éstas a los signos lingüísticos) en la humanización, señalando que la actividad es el motor de lo que nos convierte en humanos (Blanck, 1998). Pero en el marxismo los objetos son herramientas externas, sometidas al control y planeación de los seres humanos. El nuevo materialismo, que retoma de Baruch Spinoza una concepción distinta del cuerpo y los objetos atravesada por lo emocional y por fuerzas múltiples, abre el vínculo entre objetos y humanos en direcciones más plurales que el marxismo tradicional, como lo muestran los desarrollos teóricos de Deleuze, Manuel de Landa, Rosi Braidotti, Karen Barad, entre otros (véase Montag y Stolze, 1998). 
se modifica el mundo material en su interacción con los humanos, y ese proceso es un flujo continuo, con bordes provisorios e inestables. ${ }^{6}$

Desde esta perspectiva, la indagación histórico-educativa se va desplazando desde las preguntas por el ser de las cosas, definido de manera estática y definitiva, a las preguntas por el devenir, sin presuponer que se sabe lo que son o lo que pueden hacer los artefactos. Siguiendo la veta de los materiales, la investigación tiene que prestarle atención a la materialidad de los objetos, a su presencia y hechura concreta, porque juegan un papel en la complejidad de las redes; no son un efecto posterior o secundario, sino que son co-constitutivos de su tejido.

Pensando en el devenir de los objetivos, si se las considera como fuentes en la historia de la educación, entonces no puede tomárselas como historias completas y acabadas; como dice Carolyn Steedman acerca de los documentos, lo que se encuentra en el archivo son "historias capturadas a mitad de caminho [...], discontinuidades" (Steedman, 2002, p. 45). Pensando en el movimiento y el devenir de los objetos, es necesario que se consideren "las especificidades, los contextos locales y la significación global” (Lawn y Grosvenor, 2005, p. 10), los viajes, las adaptaciones que se hacen a través de y en la cultura material, la biografía social de los objetos; y es igualmente necesario que se investigue de qué están hechas, cuáles son las posibilidades de sus materiales, la historia del diseño e ingeniería de su confección, su interacción con un ambiente determinado, así como sus transformaciones.

Podría sintetizarse, entonces, este giro de la teoría y la investigación sobre la cultura material como el poner en movimiento a los objetos, no como acción externa realizada por los humanos, sino por medio de una escucha o una sensibilidad mucho más atenta al propio movimiento de las cosas, a sus devenires, a sus derrames, como los llama Ingold (2013). En esa dirección, la historia material de la educación asume una sensibilidad etnográfica, una voluntad de cartografiar o documentar las experiencias que involucraron a personas y objetos a través de sus huellas materiales, tomadas ellas también como materia que sigue transformándose en su contacto con los investigadores, como se planteará en el apartado siguiente.

6 Estas teorías tienen presupuestos filosóficos complejos, cuya exposición excede largamente lo que puede plantearse en este texto pero que, sintéticamente, puede referirse a Spinoza, Marx, Heidegger y sobre todo a Merleau-Ponty y Deleuze, corrientes que tienen muchos puntos de discordancia pero que coinciden en la centralidad de lo material en la experiencia humana. Véase Steil y Carvalho (2015). 


\section{EI trabajo con las fuentes desde la perspectiva del giro material}

Los presupuestos teóricos e historiográficos de esta posición son, entonces, más complejos que los de un materialismo ingenuo o los de un interaccionismo lineal entre entidades pre-constituidas; también se distancian de las preguntas hermenéuticas sobre el sentido que los humanos construyen sobre los objetos. El giro material invita a los investigadores a incluir cuestiones relativas a las temporalidades heterogéneas que se condensan en los artefactos y a prestarle atención a las múltiples posibilidades que ellos abren. En esta sección, quisiera referirme a mi propia investigación sobre los uniformes escolares, un trabajo que lleva ya casi dos décadas y en cuyo curso el giro material se fue afirmando, deteniéndome en el uso de fotografías para dar cuenta de la historia de la vestimenta escolar desde un punto de vista material (Dussel, 2005).

Los uniformes escolares son objetos, y los objetos, dice Lorraine Daston, "hablan; no solamente repiten. No son instrumentos para grabar y reproducir la voz humana" (Daston, 2006, p. 11). Su materialidad juega un rol en la complejidad de las redes; no es un efecto posterior sino co-constitutivo de su tejido. En esa materialidad, hay una dimensión visual muy relevante: los uniformes cuentan un código social a través de rasgos visuales como los colores, estilos y formas. Pero sobre esta condición visual se impone otra: los uniformes en mi investigación llegaron sobre todo a través de imágenes, básicamente fotografías tomadas en ambientes escolares. ¿Qué tipo de huellas son las fotografías de los uniformes en la escuela? ¿Qué relaciones pueden establecerse entre la presencia física de esos objetos y los objetos-imágenes que las presentan ante nosotros, los investigadores? La respuesta parece sencilla, pero no lo es tanto cuando se deja de pensar a las fotos meramente como representaciones y se empieza a considerar su propia existencia como artefactos que construyen una memoria sobre el pasado.

Trabajar con fotografías ha implicado problematizar el lugar central que han tenido por más de un siglo como representaciones visuales privilegiadas (Dussel, 2015), y la noción de que la fotografía es un "testigo" que captura "objetivamente" un momento histórico que después se transporta casi sin cambios hasta el presente (Daston y Galison, 2007). Esa problematización se apoya en un cuerpo creciente de investigaciones que debaten el uso de fotografías como evidencia sin mediaciones (Nóvoa, 2002). En estas investigaciones, las fotografías son consideradas en tanto artefactos materiales, como entidades que tienen su propia historia o biografía social y que juegan un rol activo en la producción de sentido como actantes no humanos en las redes que conforman lo 
social (Dussel \& Priem, 2017). Las fotografías tienen que ser estudiadas dentro de las trayectorias materiales y afectivas que marcaron su vida como artefactos; en esa trayectoria, la pregunta de por qué algunas fotografías sobrevivieron y otras no lo hicieron se vuelve importante, y atraviesa a los archivos oficiales y no oficiales, e incluso a las colecciones personales. En palabras de Elizabeth Edwards, la historia de las fotografías es tanto "una historia afectiva como efectiva", una concreción de narrativas históricas particulares que ensamblan artefactos, afectos y personas de maneras plurales (Edwards, 2015, p. 325).

En esta reconsideración de la fotografía, una dimensión importante es revisar la relación de la fotografía con el tiempo. La emergencia de la fotografía, un medio que define sus imágenes por el lapso de tiempo que la película o el sensor digital está expuesto a la luz, "reveló el nuevo poder humano de capturar instantes de tiempo específicos" (Mirzoeff, 2015, p. 23) y archivarlos para futuros espectadores. Como "medio basado en el tiempo" (time-based media), la fotografía apareció como un signo que traía el pasado al presente, y expandía la temporalidad del presente por la presencia de fragmentos activos del pasado. La fotografía, junto con el cine, puso nuevos estándares de "precisión, memoria, cognoscibilidad" (Doane, 2002, p. 24) para cualquier registro de la cultura. Pero también inició la difusión del impulso archivístico, la presión para registrar la vida y para guardar esos registros como unidades separadas y aisladas - una especie de liberación del deseo de archivo que continúa ampliándose con los medios digitales.

Siguiendo esta perspectiva teórica y metodológica, la fotografía como fuente histórica, considerada desde su materialidad como registro, conlleva entonces temporalidades complejas. El tiempo actual de la investigación está hecho de este encuentro de tecnologías, impulsos archivísticos, signos, artefactos y cuerpos que traen consigo distintas sensibilidades y miradas. La historiadora francesa Arlette Farge plantea que las fotografías son "el latido del tiempo" que recuerda que había un futuro en el pasado que se está mirando; son heridas del tiempo, pasajes, breves llamados, como cuando se perciben detalles pasajeros que abren conexiones entre el presente y los mundos que ya han sido enterrados y desaparecidos (Farge, 2006, p. 106). La referencia a la herida afirma la necesidad de tener en cuenta la historicidad de las imágenes y los eventos que se están considerando, y reconocer los desafíos epistemológicos y éticos del encuentro con los registros del pasado.

Por otro lado, a las consideraciones anteriores sobre el giro material puede sumarse la perspectiva del nuevo feminismo materialista, que plantea la necesidad de tener en cuenta que el conocimiento está in-corporado en sujetos, particularmente en la posición de el/la investigador/a y en cómo esa posición es afectada por los registros de la investigación. La onto-epistemología feminista pide a las/los investigadores "tomarse en serio nuestro propio involucramiento, 
complicado, implicado, conectado, in-corporado, en la producción de conocimiento", y también comprometerse con una noción del material como "vibrante", como agente que co-define "las micro-intensidades del aquí y ahora" (Taylor \& Ivinson, 2013, pp. 666 y 667). En este enfoque, la indagación histórica tiene que cuestionar las fronteras difusas de lo material y las delimitaciones cristalizadas de sujeto y objeto de investigación, y considerar las relaciones de las/os investigadoras/es con los restos materiales del pasado como conexiones dentro de redes de actores humanos y no humanos, con sus saberes y afectividades.

Tomando como base mi propia investigación sobre los uniformes, esta aproximación permite pensarlos como objetos que son constitutivos de la experiencia de la escolarización, que demarcan distintos márgenes de libertad (por ejemplo, a niñas y niños), distinguen entre los actos públicos del cuerpo y los íntimos, y permiten interacciones particulares con los materiales y texturas del artefacto, entre otros aspectos. Los objetos son puestos en movimiento; sus trayectorias se vuelven más significativas, forzándonos a pensar sobre las fronteras entre espacios y las transiciones que puntúan la vida escolar y configuran experiencias particulares de espacio y tiempo (Burke, 2017). En esa dirección, los reglamentos de vestimenta, los cortes de pelo y otros rasgos de las culturas materiales son objetos que se movilizan en redes porosas e inestables, y que traducen las acciones y creencias de un espacio a otro. De esto se deduce que la subjetividad de los estudiantes o los docentes no puede ya ser pensada solamente como el resultado de la interrelación de los signos definidos por los discursos sino como el efecto de la co-presencia y del intercambio entre los objetos, los seres humanos y los eventos en espacios particulares donde se encuentran las trayectorias inconclusas e indefinidas (Massey, 2005).

El nuevo materialismo feminista subraya que esta co-presencia y combinación es afectada por la presencia del investigador o investigadora, quien entra a través de la red epistémica en una relación visible y sensible con los objetos, los humanos y los eventos. Este tipo de reflexividad es aún más importante en el caso de las/os historiadoras/es, cuyos lazos con el pasado están mediados por los rastros disponibles y por el marco de inteligibilidad de su enfoque historiográfico, un marco que entreteje conceptos y afectos en una onto-epistemología que inscribe lo personal en sus puentes con lo político (Millei et al, 2018).

De esa manera, las fotografías entran en la red que conforma la investigación no como fuentes autónomas e independientes de quien las mira, sino dentro de las series epistémicas, que son también afectivas, de las/os historiadoras/es. En mi caso, eso implicó revisar mi vínculo con los uniformes y también con las fotografías escolares, recuperando una memoria sensible sobre su producción y circulación que permeaba el vínculo con esas fuentes y sometiéndola a revisión y crítica. Es importante aclarar que esta posición no implica que no se pueda ir más lejos que 
una ego-historia; si bien en algunos casos la tendencia puede ser a encerrarse en un loop de reflexividad, en los más logrados ha supuesto configurar conexiones más rigurosas entre el pasado y el presente, y un trabajo con las fuentes más cuidadoso y detallado, atento a los detalles y las relaciones con y a través del tiempo.

\section{Nuevas preguntas a la historia de la educación}

La perspectiva que se ha sostenido en este artículo quiere resistir a la fascinación o el fetichismo de los objetos, aunque sin duda entabla una relación amorosa con ellos, esto es, un acercamiento íntimo para producir una escucha atenta a sus devenires. En esa dirección, considero que el giro material plantea nuevas preguntas a la historia de la educación, preguntas que prestan atención al detalle, a las minucias, a lo aural y lo táctil que emerge en el vínculo con los artefactos.

En el cierre de este artículo, quiero retomar los aportes de dos grandes teóricos que han contribuido a revisitar lo material con otra sensibilidad y apertura, y que permiten también pensar en las nuevas materialidades que se están configurando en los espacios educativos digitales y virtuales. El primero de esos autores es Walter Benjamin, que escribió un relato sobre el pupitre - ese objeto que, para algunos pedagogos actuales fascinados con las nuevas tecnologías, debería ser condenado a un rincón de los museos por estático y anticuado - que merece la pena releerse varias veces. El texto, escrito en algún año entre 1932 y 1938 y nunca publicado en vida de su autor, empieza así:

El médico encontró que yo era miope. Y me recetó no sólo unas gafas, sino también un pupitre. Estaba construido de una manera ingeniosa. Se podía variar el asiento de tal forma que se colocaba más próximo o más alejado del tablero de plano inclinado que servía para escribir; tenía además un travesaño horizontal en el respaldo que brindaba su sostén a la espalda, sin mencionar el pequeño estante regulable que coronaba el todo. El pupitre cerca de la ventana se convirtió pronto en mi sitio preferido. El pequeño armario que estaba oculto debajo del asiento no sólo contenía los libros que necesitaba en el colegio, sino también el álbum de sellos, además de otros tres que comprendían la colección de postales. (...) Más de una vez, cuando volvía del colegio, lo primero que hacía era celebrar el reencuentro con mi pupitre convirtiéndolo en campo de acción de cualquiera de mis más caras ocupaciones, como las calcomanías... (Benjamin, 1987, p. 95-96). 
El pupitre, que no estaba en la escuela sino en la casa, a salvo de las miradas socarronas de sus compañeros, era para Benjamin su refugio, su lugar de acopio, de juegos y de aprendizajes; ahí podía conectar a las figuritas con los manuscritos medievales, leer a Dickens y Freytag, y viajar, según lo cuenta en los párrafos que siguen, hasta Babel, Bagdad, Alaska, El Cairo o Delfos. Ahí, en esa jurisdicción propia que organizaba con permiso médico, podía ponerle a los cuadernos de clase otros derechos, anulando los escolares; podía pisar nuevos continentes para sus saberes y su imaginación. Yendo a la materialidad del objeto, para Benjamin era importante que el mueble tuviera un tablero, un estante, un pequeño armario y un respaldo; importaba que estuviera al margen de la circulación habitual, sometido a su propia legislación, aunque conectado y alimentado por los códigos escolares -por ejemplo de la cultura escrita-. ¿Daba lo mismo que fuera una silla, o una tabla sin escondites ni rincones? ¿Sería igual si el objeto no fuera escolar, y si la transgresión no consistiera precisamente en sustraerlo de la órbita de la escuela? No tengo dudas de que Benjamin diría que no, que la experiencia política de la lectura y del saber se revela y se despliega en esos detalles.

La segunda referencia es a Michel Foucault, y en este caso se trata de otro pequeño gran texto titulado "Los espacios otros" (Foucault, 1999), originalmente una conferencia pronunciada en 1967 en el Círculo de Estudios Arquitectónicos y escrita durante un viaje a Túnez (una vez más, los lugares importan). Es un texto lleno de imágenes y de juegos de palabras, en el que Foucault habla del espacio como el gran lente para mirar la experiencia contemporánea, que él ve ya más centrada en la simultaneidad, la yuxtaposición, la proximidad y la distancia y no tanto en la historia, como había sido hasta mediados del siglo XX. El espacio es, para Foucault, una puerta de entrada para analizar lo heterogéneo, lo múltiple, lo que va de a pie, lo disperso; su interés central es por los "espacios otros", que para él no son las utopías (espacios irreales) sino las heterotopías, emplazamientos reales que contestan o invierten los lugares habituales. Pone como ejemplo de estos espacios las heterotopías de crisis o pasaje (internados o colegios, hotel de viajes de boda, servicio militar, misiones jesuíticas) y las de desviación (manicomios, geriátricos, cárceles); también analiza el cementerio, el cine, el jardín y la alfombra como espacios otros en relación con los lugares culturales comunes, que condensan en un espejo fantasmático la vida urbana contemporánea.

En el párrafo final, Foucault habla de los barcos, y vale la pena retomar esta imagen porque la educación ha sido, muchas veces, considerada con la metáfora del viaje, del barco o de la aventura (Charbonnel, 1991). Foucault dice que hay que preguntarse por qué el barco ha sido no solamente el mayor instrumento de desarrollo económico hasta ese momento, sino también "la mayor reserva de imaginación". Y cierra con estas palabras: "La nave es la heterotopía por 
excelencia. En las civilizaciones sin barcos los sueños se secan, el espionaje sustituye la aventura, y la policía a los corsarios" (Foucault, 1999, p. 26).

En las civilizaciones sin barcos los sueños se secan: es una frase para dejar resonando. Pensando en sus ecos en el tiempo presente, el riesgo de que los sueños se sequen, sin barcos y sin pupitres, es cada vez mayor en una tecnocultura orientada a la automatización y a la maximización del beneficio individual, entendido predominantemente en términos capitalistas. Los espacios especializados y retirados de la circulación global son mal vistos dentro del esquema de la sociedad de la transparencia (Han, 2013), que quiere que todo sea visible, medible, controlable y predecible, sin patas y sin cuerpo, alojado en la nube; y aunque la metáfora de la navegación es una de las más pregnantes en el espacio virtual, las exploraciones en las plataformas digitales son día a día menos libres, orientadas como están por algoritmos que buscan anticipar nuestros deseos y organizar los pasos de manera económica, eficiente, sin pérdida de tiempo. Las neurociencias prometen programar el aprendizaje para que cada vez se parezca menos al viaje y más a un recorrido predefinido y garantizado. Por otra parte, en la era del total surveillance y de Citizen Four, nada más real que el dicho de que el espionaje sustituye a la aventura.

Sin embargo, habría que evitar la tentación apocalíptica, y también la nostálgica. Siguiendo la metáfora del barco, habría que ver, con sensibilidad benjaminiana, si las naves espaciales de Star Wars y los joysticks de los videojuegos pueden operar como nuevos espacios otros, indagando en qué medida habilitan recovecos y escondites para que las nuevas generaciones inicien sus propias aventuras. Quizás esa mirada ayude a encontrar, en esas superficies en principio planas y sometidas al control de grandes corporaciones, materialidades y espacios otros donde se produzcan encuentros con otros mundos, y donde puedan acumularse y transmitirse nuevos registros de la experiencia humana. Las nuevas sensibilidades que aporta el giro material a la historia de la educación puede contribuir a encontrar o crear esos espacios otros en el cruce entre la historia y el presente, y en la investigación abierta y atenta al devenir de los objetos y de los humanos.

\section{REFERENCIAS}

Aguirre Lora, María Esther (2001). Enseñar con textos e imágenes. Una de las aportaciones de Juan Amós Comenio. Revista Electrónica de Investigación Educativa, 3 (1). Consultado el 12 de enero de 2019 en: http://redie.uabc.mx/vol3no1/contenido-lora.html 
Appadurai, Arjun (ed.) (1986). La vida social de las cosas. Perspectiva cultural de las mercancías. México, DF: Grijalbo/CONACULTA.

Arata, Nicolas (2016). La escolarización de la ciudad de Buenos Aires (1880-1910). Tesis Doctoral, Doctorado en Ciencias con Especialidad en Investigación Educativa, Departamento de Investigaciones Educativas del CINVESTAV, México.

Benjamin, Walter (1987). El pupitre. In: Infancia en Berlin hacia 1900. Madrid: Alfaguara, pp. 95-98. (Escrito originalmente entre 1932 y 1938).

Benjamin, Walter (2005). Libro de los Pasajes. Edición a cargo de Rolf Tiedemann. Madrid: Akal. (Escritos incompletos, producidos entre 1927 y 1940, editados póstumamente).

Barra, Valdeniza Maria Lopes da (2016). Da pedra ao pó. O itinerário da lousa na escolar pública paulista do século XIX. Goiânia: Gráfica Universidade Federal de Goiânia.

Blanck, Guillermo (comp.) (1998). El problema del desarrollo cultural del niño y otros textos inéditos. Buenos Aires: Editorial Almagesto.

Burke, Catherine (2017). Feet, footwork, footwear, and "being alive" in the modern school, Paedagogica Historica. 54: 1-2, pp. 32-47.

Castro, Raquel Xavier de Souza, y Gaspar da Silva, Vera Lucia (2012). Cultura material da escola: entram em cena as carteiras. In: Gaspar da Silva, Vera Lucia y Petry, Marilia Gabriela (eds.). Objetos da Escola. Espaços e lugares de constituiçao de uma cultura material escolar (Santa Catarina - Séculos XIX e XX). Florianópolis: Editora Insular, pp. 169-186.

Cucuzza, Héctor Rubén y Pineau, Pablo (2002). Para una Historia de la Enseñanza de la Lectura y Escritura en Argentina. Del catecismo colonial a La Razón de mi Vida. Buenos Aires: Miño y Dávila Editores.

Charbonnel, Nanine (1991). Les aventures de la métaphore. Strasbourg: Presses Universitaires de Strasbourg.

Chartier, Anne-Marie (2004). Enseñar a leer y escribir. Una aproximación histórica. México: Fondo de Cultura Económica.

Daston, Lorraine (2006). Things That Talk. Object Lessons from Art and Science. New York: Zone Books.

Daston, Lorraine \& Galison, Peter (2007). Objectivity. New York: Zone Books.

Doane, Mary-Ann (2002). The Emergence of Cinematic Time. Modernity, Contigency, the Archive. Cambridge, MA: Harvard University Press.

Dussel, Inés (2005). The shaping of a citizenship with style: A history of uniforms and vestimentary codes in Argentinean public schools. In: Lawn, Martin \& Grosvenor, Ian. Materialities of Schooling. Design, Technology, Objects, Routines. Oxford, UK: Symposium Books, pp. 97-124. 
Dussel, Inés (2015). Historia de la educación y giro visual: Cuatro comentarios para una discusión historiográfica. In: Aguirre Lora, María Esther (comp.) Narrar historias de la educación. Crisis y alquimia de un oficio. México, D.F.: Ediciones del ISSUE-UNAM y Bonilla Artigas Editores, pp. 451-484.

Dussel, Inés (2018). The digital classroom. A historical consideration on the redesigning of the contexts of learning. In: Grosvenor, Ian \& Rasmussen, Lisa Rosen (eds.). Making Education: Material School Design and Educational Governance. New York: Springer Verlag, pp. 173-196.

Dussel, Inés \& Priem, Karin (2017). The visual in histories of education: A Reappraisal. Paedagogica Historica. vol. 53, no. 6, pp. 641-649.

Edwards, Elizabeth (2015). Photography: A Strong History? In: Caraffa, Constanza \& Tiziana. Serena (eds) Photo Archives and the Idea of the Nation. Berlin: Walter De Gruyter, pp. 321-329.

Escolano Benito, Agustín (2012). Las materialidades de la escuela (a modo de prefacio). In: Gaspar da Silva, Vera Lucia y Petry, Marilia Gabriela (eds.). Objetos da Escola: Espaços e lugares de constituição de uma cultura material escolar (Santa Catarina Séculos XIX e XX). Florianópolis: Editora Insular, pp. 11-18.

Farge, Arlette (2006). Le temps logé en la photographie. À partir de Barthes et Kracauer. Intermédialités. 7, pp. 205-213.

Fernández Enguita, Mariano (2017). Más escuela y menos aula. Madrid: Morata.

Foucault, Michel (1976). Vigilar y Castigar: Nacimiento de la prisión. México DF: Siglo XXI.

Foucault, Michel (1999). Espacios Otros. Versión. Estudios de Comunicación y Cultura. 9, pp. 15-26.

Gaspar da Silva, Vera Lucia \& Petry, Marilia Gabriela (orgs.) (2012). Objetos da escola: Espaços e lugares de uma cultura material escolar (Santa Catarina - Séculos XIX e $X X)$. Florianópolis: Insular.

Granja Castro, Josefina (2004). Métodos, aparatos y máquinas para la enseñanza en México en el siglo XIX. Imaginarios y saberes populares. Barcelona-México: Ediciones Pomares.

Grosvenor, Ian (2012). Back to the future or towards a sensory history of schooling. History of Education, 41 (2), pp. 675-687.

Gvirtz, Silvina (1999). El discurso escolar a través de los cuadernos de clase. Argentina (1930-1970). Buenos Aires: EUDEBA.

Han, Byung-Chul (2013). La sociedad de la transparencia. Barcelona: Herder Editorial. Ingold, Tim (2012). Toward an Ecology of Materials. Annual Review of Anthropology, 41: pp. 427-442. 
Ingold, Tim (2013). Making: Anthropology, archeology, art and architecture. New York \& London: Routledge.

Latour, Bruno (2005). Reensamblar lo social. Una introducción a la teoría del actor en red. Buenos Aires: Manantial.

Lawn, Martin \& Grosvenor, Ian (2005). Introduction: The Materiality of Schooling. In: Lawn, Martin \& Grosvenor, Ian (eds.). Materialities of schooling. Design, Technology, Objects, Routines. Oxford, UK: Symposium Books, pp. 1-15.

Le Goff, Jacques (1986). Los intelectuales en la Edad Media. Barcelona: Gedisa.

Massey, Doreen (2005). For Space. London: Sage.

Meda, Juri (2016). Mezzi di Educazione di Massa. Saggi di storia della cultura materiale della scuola tra XIX e XX secolo. Milan: Franco Angeli.

Millei, Zsuzsa; Piattoeva, Nelli; Silova, Iveta \& Aydarova, Elena (2018.) Hair Bows and Uniforms: Entangled Politics in Children's Everyday Lives. In: Silova, Iveta, Millei, Zsuzsa \& Piattoeva, Nelli. Childhood and Schooling in (Post) Socialist Societies: Memories of Everyday Life (New York: Palgrave Macmillan), pp. 145-162.

Miller, Daniel (ed.) (2005). Materiality. Durham \& London: Duke University Press.

Mirzoeff, Nicholas (2015). How to See the World. A Pelican Introduction. London: Penguin Books.

Monfort, Marie (2017). Le décor des écoles de Paris dans l'entre-deux-guerres ou le bien-être à l'école. In: ACAOAF [Association des Conservateurs des Antiquités et Objets d'Artde France] (2017). Regards sur le patrimoine mobilier de l'enseignement scolaire et universitaire. Arles: Errances/Actes du Sud, pp. 131-144.

Montag, Warren; Stolze, Ted (1998). The New Spinoza. Minneapolis: The University of Minnesota Press.

Moreno Martínez, Pedro (2005). The History of School Desk Development in Terms of Hygiene and Pedagogy in Spain (1838-1936). In: Lawn, Martin \& Grosvenor, Ian (eds.). Materialities of schooling. Design, Technology, Objects, Routines. Oxford, UK: Symposium Books, pp. 71-95.

Nóvoa, António (2002). Ways of Saying, Ways of Seeing: Public Images of Teachers (19th-20th Centuries). Paedagogica Historica. 36:1, pp. 20-52.

Pineau, Pablo (dir.) (2014). Escolarizar lo sensible. Buenos Aires: Ed. Teseo.

Santoni Rugiu, Antonio (1994). Nostalgia del maestro artesano. México DF: Universidad Nacional Autónoma de México.

Serra, María Silvia (2011). Cine, escuela y discurso pedagógico: Articulaciones, inclusiones y objeciones en el siglo XX en Argentina. Buenos Aires: Editorial Teseo. 
Szir, Sandra (2007). Infancia y cultura visual. Los periódicos ilustrados para niños (1880-1910). Buenos Aires: Miño y Dávila editores.

Steedman, Carolyn (2002). Dust. The Archive and Cultural History. New Brunswick, NJ: Rutgers University Press.

Steil, Carlos Alberto e Carvalho y Moura, Isabel Cristina de (2015). Diálogos imaginados entre Thomas Csordas y Tim Ingold. In: Citro, Silvia; Bezerril, José y Mennelli, Yanina (cords.). Cuerpos y corporalidades en las culturas de las Américas. Buenos Aires: Biblos, pp. 43-58.

Taylor, Carol \& Ivinson, Gabrielle (2013). Material feminisms: new directions for education. Gender and Education. 25:6, pp. 665-670.

Van Den Driessche, Maarten (2009). Architecture of the educational complex in the Belgian context. University Ghent: Unpublished doctoral thesis.

Vidal, Diana y Gaspar da Silva, Vera Lucia (2011). Por uma história sensorial da escola e da escolarizaçao. In: Castro, C. A. (org.). Cultura material escolar: a escola e seus artefatos (MA, SP, PR, SC e RS), 1870-1925. São Luis: EDUFMA/Café \& Lápis, pp. 19-41.

Vottero, Michael (2017). Autour de la table Fêret du Président Carnot, le mobilier d'école à l'Exposition Universelle de 1889. In: ACAOAF [Association des Conservateurs des Antiquités et Objets d'Art de France] (2017). Regards sur le patrimoine mobilier de l'enseignement scolaire et universitaire. Arles: Errances/Actes du Sud, pp. 83-89.

Texto recibido el 3 de mayo de 2019. Texto aprobado el 18 de junio de 2019. 